\title{
Library Usage by the Medical Students of a Tertiary Medical College in Chattogram
}

Maliha Ata ${ }^{1}$

Rozina Hoque ${ }^{1}$

Asma Mostafa ${ }^{2}$

Happy Rani Barua ${ }^{1}$

'Department of Pharmacology

Chattogram Maa-O-Shishu Hospital Medical College Chattogram, Bangladesh.

${ }^{2}$ Department of Anatomy

Chattogram Maa-O-Shishu Hospital Medical College Chattogram, Bangladesh.
*Correspondence to:

\section{Dr. Maliha Ata}

Associate Professor

Department of Pharmacology

Chattogram Maa-O-Shishu Hospital Medical College Chattogram, Bangladesh.

Mobile : +8801910837966

Email:dr.maliha59@gmail.com

Date of Submission : $\quad$ 08.07.2019

Date of Acceptance : $\quad 10.09 .2020$

www.banglajol.info/index.php/CMOSHMC

\begin{abstract}
Background: The medical college library plays an important role in enhancing the academic achievements of medical students. In order to improve the quality of library services this study provided an assessment of the impact of the library services on undergraduate medical student learning behavior.

Materials and methods: This was a cross-sectional descriptive type of study. The study used a self-designed questionnaire. The study sample was 200 undergraduate medical students. The questionnaire was administered to them at the end of their lecture class.
\end{abstract}

Results: The primary reason for going to the library was self study (68\%) refer text (37\%) and group study (36\%). Only $38.55 \%$ of the respondents visited the library on a daily basis, 50.5\% students visit library when necessary and $10.5 \%$ student use library 2-3 times a week. All students (100\%) are aware about availability of text books in the library. $60.5 \%$ students know that journals are available in their library, $52 \%$ know about dictionaries, $56.55 \%$ know of having internet, $62.5 \%$ students know that computers are available in library. $46.5 \%$ students said that their internet of institutional library is somewhat helpful. Noise (67.5\%), insufficient space (66\%), lack of interent access (46\%) and lack of computers(44.5\%) might have negative influence on the students in library visit.

Conclusion : The study suggested that fulfillment of more needs to be done to promote self directed learning. The usage of library, its resources and services need to be increased.

Key words: Library; Medical students; Self learning process.

\section{INTRODUCTION}

Acceleration of information is very important implications for the education of health professionals including medical students now a days. Informations are vital, indispensable resources required in any academic environment, so acquiring and using information are critical and important activities. Any academic environment is incomplete without providing information. In present era, medical students are actively using libraries and their resources as their main information sources. We must agree that place where students can acquire knowledge without any boundary is library which also enhances the field of inspiration for increasing habit of reading books. The academic library should expedite the transfer of knowledge by providing resources for all who work and study in the institution. Though formal education in real sense starts through informal self-learning and for self learning process there is no alternative of library ${ }^{1,2}$. As medical science is continuously advancing discipline, the proper utilization of medical library both by students and teachers is a very significant for upgrading medical knowledge, skill and information regarding new innovations, views, theories, and latest treatment for better patient care, medical education and research with the recent advances through self-directed education ${ }^{3,4}$. 
Medical education is often criticized for it's failure to promote a sense of responsibility among medical students for their own learning and over reliance on text books for information and traditional and didactic lectures ${ }^{5,6,7}$. So, a library can be a richest resource for any academic institution especially medical college hospital and proper utilization of library as a resource is necessary. Rankin noted that until early 1990, there were few library users ${ }^{8}$. The 1990 s saw a growing interest in student's library use and their utilization that library is needed to understand and address their needs ${ }^{9}$. There should be an expedition to know about the type of library materials preferred by medical students is an important factor to determine and satisfy their information needs. Although an institution may have the best stocked libraries, the utilization of the libraries by the students need not simply depend on the number of books and journals in the library, it also depends on the general environment of the library, distance from the place of the residence ${ }^{10,11}$. A library with an internet facilities make the academic environment of all students complete for the knowledge acquiring ground. Without the aid of internet resource the educational activities lacks the empowering effect of technology. The improvement of evidence based treatment, quality of care and to keep up to date knowledge, the use of internet by medical professionals is very essential. Only formal classroom lectures are not complete solution of learning medical science. Information should be collected by the students by their own self learning process to develop adequate professional competence ${ }^{12}$. As location is not a factor to gain information from internet, this could be an excuse for students not to present physically to read books. For this reasons internet has replace the library for gathering knowledge and for research purpose. Many factors such as personal preferences, the general environment in the library, inconveniences of the working hours, and distance from the place of residence may also influence the use of the library. There are differences in utilization pattern and concerns of library services among the undergraduate and postgraduate medical students. The utilization of a library as an appliance of learning is determined by the success with which it is able to provide the user with the information that he/she seeks ${ }^{11,13,14}$. An attempt is necessary to find out the pattern of the utilization of the library occasionally in any large institution, which may helpful in formulating new policies and improving services and providing information about what is expected as against what is available ${ }^{15}$. So this study was undertaken among medical students to determine usage pattern of the library information resources, services and satisfaction of the users in a Tertiary Medical College Hospital in Chattogram.

\section{MATERIALS AND METHODS}

This is a cross sectional study that was conducted among medical students of Chattogram Maa O Shishu Hospital Medical College during March to May, 2019. Investigators went to the end of the lecture class of undergraduate MBBS where they informed about the study to students and sample was collected by systematic random sampling. Those who were selected as a sample a self designed pretested questionnaire was distributed to them and those students completed the questionnaire and submited it to the investigators. During collection of each questionnaire was checked whether all answers were ticked or not. If incomplete, instructed that student to complete it. After collection of questionnaire, data was compiled and analyzed by computer based software SPSS 18 .

All respondents (Medical students of Chattogram Maa-OShishu Hospital Medical College) were briefed about the study. Verbal consent was taken from respondents. Confidentiality was maintained. Withdrawal right of respondents was preserved. There was no scope of sample collection or painful procedure or financial loss. So there was no chance of ethical violation. Moreover Ethical Committee approval was obtained from the Institutional Review board of Chattogram maa $\mathrm{O}$ Shishu Medical College, Chattogram prior commencement of the study.

\section{RESULTS}

The study population included 200 undergraduate medical students. Maximum i.e, 79\% of medical students are using both internet and library as source of information for academic purpose. $12.5 \%$ students only using library as a source of information for academic purpose. Only $2.5 \%$ students using only internet as a source of information for academic purpose. $46.5 \%$ students say that their institutional library is somewhat helpful, $37 \%$ student say that institutional library is helpful and $16.5 \%$ students say that their institutional library not helpful for them in academic purpose ( Figure 1).

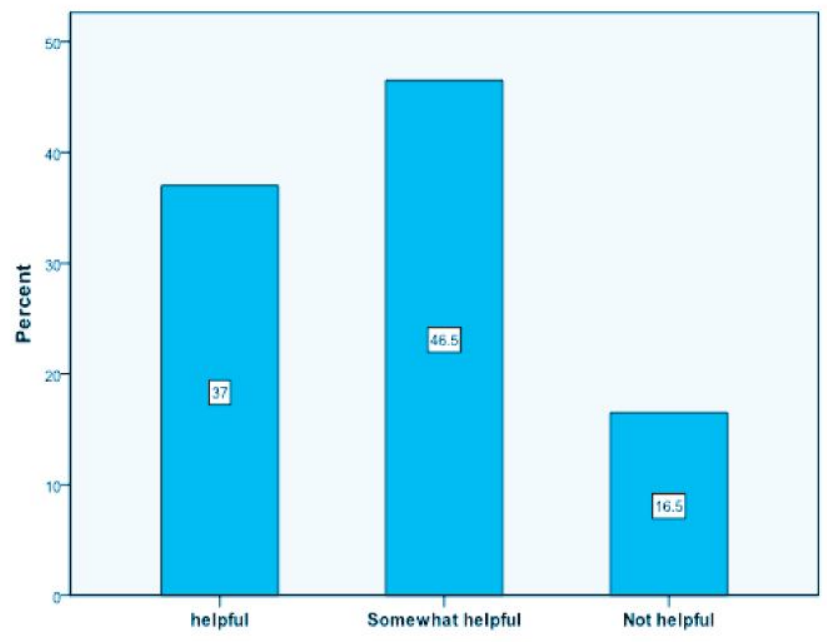

Figure 1 : Helpfulness of the library in academic purpose

Table I shows that $68 \%$ students use library to self study purpose, $37 \%$ students use library to refer text , $36 \%$ students use for group study, $23.5 \%$ students use library to collect past question file, for gossip $16 \%$ students use library, to refer journal only $4.5 \%$ students use library. 
Table I : Purpose of visiting library

\begin{tabular}{lrc} 
Purpose of using library & Score & Percentage \\
Self study & 136 & $68 \%$ \\
Refer text & 74 & $37 \%$ \\
Group study & 72 & $36 \%$ \\
Internet & 68 & $34 \%$ \\
Collect past question file & 47 & $23.5 \%$ \\
Socialization with friends & 32 & $16 \%$ \\
Refer journal & 09 & $4.5 \%$ \\
Using photocopy machine & 07 & $3.5 \%$ \\
Reading newspaper & 06 & $3 \%$ \\
Get ready for seminar or & & \\
presentation & 02 & $1 \%$ \\
Refer other material & 02 & $1 \%$ \\
\hline
\end{tabular}

*Multiple response.

$50.5 \%$ students visit library when necessary, 38.55\% students visit library every day and $10.5 \%$ student use library $2-3$ times a week . 89\% students spend 2-3 hours in library, $62 \%$ students spend less than 1 hour and $49 \%$ spend more than 3 hours in library .

Table II depicts knowing available resources in library. All students $(100 \%)$ know that text books are available in their library, $60.5 \%$ students know that journals are available in their library, $52 \%$ know about dictionaries, $56.55 \%$ know of having internet, $62.5 \%$ students know that computers are available in library, 44\% students know about photocopy machine, 27\% students are aware about past question file and online data base like Hinari access are available in the library known by only $27 \%$ students.

Table II : Availability of resources in the library

\begin{tabular}{lr} 
Resources & Score ( percentage) \\
Text books & $200(100 \%)$ \\
Journals & $121(60.5 \%)$ \\
Dictionaries & $104(52 \%)$ \\
Internet & $113(56.5 \%)$ \\
Computers & $125(62.5 \%)$ \\
Photocopy & $88(44 \%)$ \\
Online data base & $34(17 \%)$ \\
Past question file & $54(27 \%)$ \\
\hline
\end{tabular}

The process of locating desired informations are somewhat easy in $43.50 \%$ students, $31.50 \%$ student find out easily, not at all easy for $21.50 \%$ students and very easy for $3.50 \%$ students. Desired informations are not adequate for $114(57 \%)$ students and adequate for 86 students (43\%).

$32 \%$ students get help from librarian rarely, $31.5 \%$ students get help from librarian in some visit and 26\% students get help in every visit. Relationship with librarian is good in $45 \%$ students, very poor in $26 \%$ students, poor in $20 \%$ students and only $9 \%$ students said that their relationship with librarian is very good. $46.5 \%$ students said that their internet of institutional library is somewhat helpful and $37 \%$ students agreed that library internet is helpful and $16.5 \%$ students said their library internet is not helpful.
Respondents were asked to indicate barriers to the use of internet institutional library. The result is shown in table III. As shown in the Table, the major barrier to use of the Internet for academic purposes is lack of internet access (54.5\%). Other barriers include lack of computers and printing machine (45\%), slow downloading (29\%), restriction of important information for payment (11.5\%), lack of internet searching skill (7.5\%) and informations are difficult to understand (4\%).

Table III : Barrier of using internet and effective use of library.

\begin{tabular}{lr} 
Barriers of using Internet & Percentage (\%) \\
Lack of internet access & $54.5 \%$ \\
Lack of computers and printing machine & $45 \%$ \\
Slow downloading & $29 \%$ \\
Important information I need on the & \\
internet are restricted for payment & $11.5 \%$ \\
Lack of internet searching skill & $7.5 \%$ \\
Information I find are difficult to understand & $4 \%$ \\
Barrier of effective use of library & Percentage (\%) \\
Noise & $67.5 \%$ \\
Insufficient space & $66 \%$ \\
Lack of internet/poor internet & $46 \%$ \\
Lack of computers & $44.5 \%$ \\
Lack of stuff & $44.5 \%$ \\
Non cooperative stuff & $23.5 \%$ \\
Inadequate ventilation & $42 \%$ \\
Lack of desired books & $22 \%$ \\
Lack of time & $16.5 \%$ \\
Little knowledge about availability of resource & $17 \%$ \\
Poor lighting & $26 \%$ \\
Other barrier & $10 \%$ \\
\hline
\end{tabular}

$39 \%$ students are unsatisfied with the utilization of the library, $33.5 \%$ of the students are satisfied and $21 \%$ of the students are highly unsatisfied and $2.5 \%$ of the students are highly satisfied with the utilization of library.

Barriers to effective use of the medical library are shown in Table III. Major barrier reported by the students are noise $(67.5 \%)$ insufficient space $(66 \%)$, lack of internet or poor internet (46\%), lack of computers (44.5\%), lack of stuff (44\%). Table IV depicts recommendation of library environment for effective use of library.

Table IV : Recommendation

\begin{tabular}{lcc} 
Recommendation & Frequency & Percentage \\
To increase seat & 184 & $92 \%$ \\
Comfortable seat arrangement & 136 & $68 \%$ \\
Adequate ventilation & 102 & $51 \%$ \\
Adequate lighting & 81 & $40.5 \%$ \\
Increase stuff cooperation & 86 & $43 \%$ \\
Drinking water facilities & 117 & $58.5 \%$ \\
Toilet facility & 109 & $54.5 \%$ \\
Separate seat for boys and girls & 68 & $34 \%$ \\
Separate seat year wise & 83 & $41.5 \%$ \\
Separate common room with locker & 98 & $49 \%$ \\
Recommendation for calm environment & 85 & $42.5 \%$ \\
\hline *Multiple response & &
\end{tabular}




\section{DISCUSSION}

This study assessed the pattern of use of medical library in a Medical College of Chattogram. Utilization of both library and internet $(79 \%)$ are major source of information by the medical students. Majority of the students informed that their medical library is somewhat helpful $(46.5 \%)$ to helpful $(37 \%)$ for the academic purpose. Most of the students using library for study related activity like self study (68\%), refer text book (37\%) and group study $(36 \%)$ in line with the findings by Shiny et al, Chatterjee et al, Shah $\mathrm{C}$ and Lal $\mathrm{P}$ and Ingle $\mathrm{GK}^{1,3,11,16}$. The purpose for visiting library for internet is less frequent (34\%). Perhaps the cause is students use internet on their personal mobile internet package or at their home or hostel. Majority of the students $(50.5 \%)$ visit library when necessary and this is similar to study of Chinchpure et al and spends 2-3 hours $(89 \%)$ in the library. $38.5 \%$ students visit library everyday and this is very similar to study of Lal P and Ingle GK, who found $41 \%$ students made daily visit to library ${ }^{16,17}$. All students opined the availability of text books in the library, majority of the students $(60.5 \%)$ said that there are journal available in the library. Process of locating desired information is somewhat easy $(43.5 \%)$ to easy $(31.5 \%)$ for most of the students. Relationship of the students with librarian is good in $45 \%$ students, but very poor in $26 \%$ students, poor in $20 \%$ students and $32 \%$ students complained that they get help from librarian rarely. Institutional library internet is somewhat helpful (46.5\%) to helpful (37\%) for most of the students. Major barriers for effective use of internet are lack of internet access (54.5\%), lack of computers and printing machine (45\%), and slow downloading $(29 \%)$. So this finding suggest to use more effective and more speedy internet in the library and provision of more computers and printing facility as updating the knowledge is necessary in medical science. So students should not only focus on text book but also need to access internet to gather knowledge at a same time. Dissatisfaction of internet facilities was also the major area of concern of study of Parande et $a 1^{18}$. Majority of the students are highly unsatisfied to unsatisfied with the utilization of the library and major area of their dissatisfaction on some physical aspects of library environment like noise, insufficient space. So their recommendations are more focused on to increase the number of seats and comfortable seating arrangements. Students also recommended toilet and drinking water facility which is similar to other study like Chatterjee et $\mathrm{al}^{3}$. About half percentage of students recommended separate common room with locker in order to avoid noise and gossiping in the library. The major limitation of our study was that we could not compare library usage pattern among under graduate students, post graduate trainees and teachers as we were unable to include post graduate trainees and teachers in this study.

\section{CONCLUSION}

Based on the analysis of the collected data, it was endowed that, the usage of library resources are very high. Most of the students use library for study purpose. Majority of students are not satisfied with the library facilities. So, the study suggests that more needs are to be fulfilled to promote self-directed learning. The students suggested from the barriers that library needs more computers and printing machine with effective and speedy internet along with improvement of some physical aspects of library like increase in space of the library with the number of seats. There is also need of toilet and drinking water facility in the library and a separate common room to avoid disturbances in the library.

\section{DISCLOSURE}

All the authors declared no competing interest. 


\section{REFERENCES}

1. M. Shiny, Mohd. S, Mohan S, Paul S, Ramesh K. A cross-sectional study on library use by medical students andnfaculties in government medical college, Thiruvananthapuram. Undergraduate Research Paper. 2006.

2. Library of Alexandria. 2008

3. Chatterjee C, Joardar GK,Bhattacharrya K, Nandy S andMisra RN. Use of Medical Library by Medical Students and Teachers in Medical Colleges of Kolkata. Indian journal of com med. 2006;31(3):204-5.

4. Romanov K, Aarnio M. A survey of the use of electronic scientific information resources among medical and dental students. BMC Med Educ. 2006;6:28.

5. Editorial Independent study. Medical Education. 1976;10(6):443-444.

6. AbrahamGJS, Dhume VG, Diniz RS. Comparison of didacdic lecture, self reading and self instruction aslearning methods in medical students of Western India. Medical Education. 1981;15(4):222-225.

7. $\quad$ Port J, Meisis HR. Teaching Library skills in third year clerkship. J Med Edu. 1982;57(7): 564-566.

8. Rankin J. A problem based medical education: effect on library use. Bull Med Libr Assoc. 1992; 80(1): 36-43.

9. Eskola EL. Information literacy and collaboration information behavior of medical students styding in the problem based and traditional curriculum. International Journal of Educational research. 2006;41(1): 407-428.

10. Goel NK, Sarpal SS, Galhotra A, Abhadeep. A study about library usage by undergraduate medical students in a medical college in North India. Natl J Community Med. 2012;3(1):89-93.

11. Shah C. Case study: Library usage at an Indian medical college. Health information And Library Journal. 2010; 28(1):77-81.

12. Haux R. Health and medical informatics education: Perspectives for the next decade. Int J Med Inform. 1998;50(1-3):7-19.

13. Masrek MN, Sahal Md. Library usage of medical students: A comparative Analysis of First Year and Third Year students in University Putra Malaysia. Procedia- Social an Behavioural Science. 2014;129:127-132.

14. Pal A, Basu J, Chaurasia VR, Ram AK. A study on library usage pattern among undergraduate medical students in a tertiary care teaching hospital in Bihar. IJHSR. 2015;5(8):309-315.

15. Rathnakara UP, Shastry R, Unnikrishnan B, Rao A, Pemminati S, Prakash S, et al. The utilization of library services by students in a medical college. J Clin Diagn Res. 2011;5(4):818-821.

16. Lal $\mathrm{P}$ and Ingle GK.Use of medical Library by undergraduate medical students in a medical college of Noth India.Indian journal of community medicine. 1999;24(2):86-88.

17. Chinchpure $\mathrm{S}$ et al. Utilization of the library and internet as a source of scientific information by the nursing students. Biomedical journal of scientic and technical research. 2018;2(4):2774-2784

18. Parande MA, Tapare VS, Borle PS. Utilization of library services by the medical students: A comparative analysis of undergraduate and postgraduate students in a medical college. International journalof medical science \& public health. 2017;6(5): 1-7. 